\title{
Caso alóctone de leishmaniose visceral canina, no município de Campo Mourão, Paraná, Brasil
}

\author{
Allochthonous case of visceral canine leishmaniasis in \\ Campo Mourão, Parana, Brazil
}

\author{
Alexandre Redson Soares da Silva ${ }^{1 *}$; Andressa Aparecida Macedo \\ Ludmila Rodrigues Moroz ${ }^{3}$; Roberta Ribeiro Fernandes ${ }^{4}$; \\ Sabrina Marin Rodigheri ${ }^{5}$; Ana Amélia Domingues Gomes ${ }^{6}$
}

\section{Resumo}

O presente relato tem por objetivo descrever o primeiro caso alóctone de leishmaniose visceral (LV) no município de Campo Mourão, Paraná, Brasil, em um canino, da raça Boxer, apresentando lesões oculares e cutâneas, linfoadenomegalia e esplenomegalia, atendido no Hospital Veterinário da Faculdade Integrado de Campo Mourão, após ter residido na cidade de Campo Grande, Mato Grosso do Sul. O diagnóstico da enfermidade baseou-se na observação direta de formas amastigotas de Leishmania spp., em linfonodos poplíteos, sugerindo ser um caso de LV, uma vez que o animal era proveniente de área endêmica para a enfermidade. A migração de cães infectados de regiões endêmicas para áreas indenes torna-se um problema para a saúde pública, uma vez que poderá permitir a instalação de novos focos, favorecendo a disseminação da doença em todo o país.

Palavras-chave: Cão, Leishmania spp., zoonose, região Sul, vigilância epidemiológica

\begin{abstract}
This report aims to describe the first case allochthonous of visceral leishmanisasis (VL) in the municipality of Campo Mourão, Parana, Brazil, in a canine, Boxer breed, with eye and skin lesions, lymphadenomegaly and splenomegaly, attended at Veterinary Hospital at the Faculdade Integrado de Campo Mourão, after residing in the city of Campo Grande, Mato Grosso do Sul. The diagnosis of the disease was based on direct observation of amastigotes of Leishmania spp., in popliteal lymph nodes, suggesting that a case of VL, since the animal came from an endemic area for the disease. The migration of infected dogs from endemic regions to areas unaffected becomes a problem for public health, since it may allow the installation of new outbreaks by encouraging the spread of disease throughout the country.

Key words: Dog, Leishmania spp., zoonosis, southern, epidemiological surveillance
\end{abstract}

\footnotetext{
${ }^{1}$ Pós-Graduando, Programa de Pós-Graduação em Medicina Veterinária, Faculdade de Medicina Veterinária e Zootecnia, Universidade Estadual Paulista "Júlio de Mesquita Filho", UNESP, Botucatu, SP. E-mail: alexandreredson@hotmail.com

${ }^{2}$ Discente, Curso de Graduação em Medicina Veterinária, Faculdade Integrado de Campo Mourão, Campo Mourão, PR. E-mail: andressa macedo13@hotmail.com

${ }^{3}$ Pós-Graduanda, Programa de Clínica Cirúrgica Veterinária, Faculdade de Medicina Veterinária e Zootecnia, Universidade de São Paulo, USP, São Paulo, SP. E-mail: ludymoroz@gmail.com

${ }^{4}$ Prof ${ }^{a}$ Assistente, Curso de Graduação em Medicina Veterinária, Faculdade Integrado de Campo Mourão, Campo Mourão, PR. E-mail: coord.veterinaria@grupointegrado.br

${ }^{5}$ Prof $^{a}$ Assistente, Faculdade Evangélica do Paraná, FEPAR, Curitiba, PR. E-mail: smrodigheri@yahoo.com.br

${ }^{6}$ Prof ${ }^{a}$ Assistente, Universidade Federal do Vale do São Francisco, UNIVASF, Petrolina, PE. Pós-Graduanda, Programa de PósGraduação em Medicina Veterinária, Área Clínica Médica Veterinária, Faculdade de Ciências Agrárias e Veterinárias, Universidade Estadual Paulista "Júlio de Mesquita Filho", UNESP, Jaboticabal, SP. E-mail: anaamelia.gomes@univasf.edu.br

* Autor para correspondência
} 


\section{Introdução}

A leishmaniose visceral canina (LVC) é causada pela Leishmania (Leishmania) chagasi no Novo Mundo e é uma infecção potencialmente fatal, de caráter zoonótico, nas Américas (BANETH, 2006). A doença acomete o homem e diversas espécies de animais domésticos e silvestres, com distintas formas clínicas e diferentes graus de severidade (BANETH, 2006; VIDES et al., 2009).

Atualmente, diversos países da América do Sul, tais como Argentina e Paraguai, vem apresentando, de forma crescente, relatos da enfermidade em cães e em humanos, entretanto, o Brasil é responsável por 90\% dos casos da América Latina (ACARDI et al., 2010; BRASIL, 2010). Entre os anos de 2000 a 2010, foram notificadas 31.098 pessoas com leishmaniose visceral (LV), em todo território brasileiro, além de ser verificado um aumento nas taxas de letalidade que elevou de três para sete o número de óbitos em cada 100 indivíduos doentes, com cerca de 200 casos fatais por ano. A maior parte dos pacientes infectados concentra-se na região nordeste, centro-oeste e sudeste do país (BRASIL, 2010).

Na região Sul do Brasil, casos autóctones de LV são escassos devido à inexistência do Lutzomyia longipalpis, considerado o principal vetor da enfermidade (THOMAZ-SOCCOL et al., 2009).

No estado do Paraná, cães e humanos com sinais clínicos compatíveis com a doença vêm sendo descritos (THOMAZ-SOCCOL et al., 2009), no entanto, estudos epidemiológicos da doença canina sugerem que esta região é considerada de baixo risco para a população. De acordo com Frehse et al. (2010), ao avaliar 364 cães no estado paranaense, para LV por meio de ensaio imunoenzimático (ELISA) e reação de imunofluorescência indireta (RIFI), $0,0027 \%$ e $0 \%$ foram positivos para a zoonose, respectivamente. Ademais, 13,73\% (50/364) destes cães foram negativos para formas amastigotas de Leishmania spp., quando avaliados por meio da citologia aspirativa por agulha fina (CAAF).
Nos estados da região Sul do país, há relatos de LV ocorridos em cães e humanos provenientes de outros estados ou países de fronteira e que vieram residir nessas regiões, por isso, são considerados alóctones ou importados (BRASIL, 2010; FREHSE et al., 2010).

Até o presente momento, de todos os animais identificados como reservatórios da doença, o cão é considerado epidemiologicamente o mais importante, pois apresenta um grande contingente de animais infectados com parasitismo cutâneo, constituindo-se o principal elo na cadeia de transmissão da doença (BANETH, 2006).

As principais manifestações clínicas na forma clássica da doença incluem mucosas pálidas, apatia, emagrecimento progressivo, caquexia, hiporexia, linfoadenomegalia, hepato e esplenomegalia (VIDES et al., 2009). Frequentemente são descritas alterações envolvendo o sistema tegumentar, digestório, renal, nervoso, locomotor e ocular, entre outros. Ademais, o quadro clínico pode se apresentar complicado devido à ocorrência de infecções oportunistas concomitantes (BANETH, 2006; VIDES et al., 2009).

A confirmação do diagnóstico da LVC é baseada nos métodos parasitológicos, sorológicos e/ou moleculares (BANETH, 2006; MARCONDES et al., 2011). O exame parasitológico fundamenta-se na demonstração de formas amastigotas do parasito em esfregaços obtidos por meio da CAAF de órgãos linfóides e, menos frequentemente, em esfregaços sanguíneos, líquido ascítico e líquido sinovial, corados com corantes de rotina, tais como Giemsa, Wright e Panótico. Trata-se de um método simples com especificidade de $100 \%$ e sensibilidade dependente do grau de parasitemia e do tipo de material biológico colhido. As formas amastigotas são reconhecidas pela sua forma esférica a ovóide, medindo $2-5 \mu \mathrm{m}$ e contendo um núcleo arredondado e um cinetoplasto alongado (IKEDA-GARCIA; FEITOSA, 2006).

Como uma das medidas de controle da enfermidade, o Ministério da Saúde recomenda que 
cães infectados por Leishmania spp. sejam submetidos a eutanásia, uma vez que o tratamento não traz a cura parasitógica, permitindo que esses animais tornem-se importantes fontes de infecção (BRASIL, 2006).

Considerando a importância zoonótica, a alta letalidade e a disseminação da LV na federação brasileira e países vizinhos, a avaliação de animais suspeitos para a enfermidade, provenientes de áreas endêmicas ou de regiões com casos da doença, tornase importante para a saúde pública, uma vez que esta zoonose e seus vetores apresentam alto potencial de disseminação e adaptação, principalmente em áreas que apresentam grande crescimento urbano, mudanças climáticas, desmatamento e más condições sócio-econômicas, evidenciados em quase todo o país (BRASIL, 2006).

\section{Relato do Caso}

Uma cadela, da raça Boxer, de dois anos de idade, com aumento da temperatura retal $\left(39,9^{\circ} \mathrm{C}\right)$, mucosas congestas, tempo de preenchimento capilar igual a um segundo, taquipnéia, linfoadenomegalia generalizada e esplenomegalia, foi atendida no Hospital Veterinário da Faculdade Integrado de Campo Mourão - PR (Figura 1).

Figura 1. (A) Fotografia de um cão com alopecia e eritema periocular, quemose e eritema facial, positivo para leishmaniose visceral. (B) Fotografia do mesmo cão, com linfoadenomegalia evidente, rarefação pilosa e eritema generalizado. (Campo Mourão, 2012).

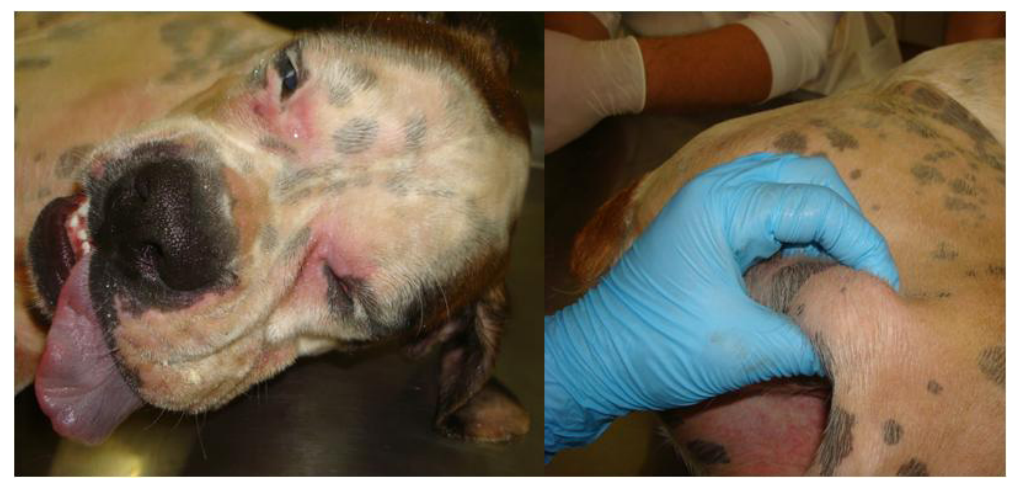

Fonte: Elaboração dos autores.

Ao exame oftalmológico verificou-se blefarite em olho direito, hiperemia conjuntival, quemose, secreção ocular purulenta e neovascularização corneana de ocorrência bilateral. O teste de Schirmmer revelou produção lacrimal de $25 \mathrm{~mm} /$ min no olho direito e $20 \mathrm{~mm} / \mathrm{min}$ no olho esquerdo, e o teste de fluoresceína foi negativo em ambos os olhos.

No sistema tegumentar, o cão apresentava descamação farinácea leve em região dorsal, eritema e discromia pilar interdigital dos membros pélvicos, hiperqueratose em região articular fêmuro-tibiotársica bilateral. Os demais sistemas apresentavamse sem alterações relevantes.
Verificou-se que o cão residia apenas há seis meses no município de Campo Mourão - PR, contudo era proveniente de Campo Grande - MS, local considerado como área endêmica para LVC.

Devido às alterações clínicas e a procedência do animal foram realizados o hemograma completo e CAAF de linfonodos submandibulares, préescapulares e poplíteos para a pesquisa de formas amastigotas de Leishmania spp. Os testes sorológicos recomendados pelo Ministério da Saúde, não foram realizados uma vez que o animal fora vacinado contra o parasita.

Os exames laboratoriais revelaram leucograma dentro dos padrões de normalidade e o eritrograma 
demonstrou anemia normocítica, normocrômica moderada e proteínas plasmáticas totais elevadas.

Por meio do exame citopatológico foi possível observar celularidade abundante, presença acentuada de hemácias, reação linfohistioplasmocitária, presença moderada de corpúsculos linfoglandulares, discreta hemossiderose e formas amastigotas típicas de Leishmania spp. no interior de macrófagos, confirmando o diagnóstico de leishmaniose (Figura 2).

Figura 2. Avaliação citológica de linfonodo de cão, acometido por leishmaniose visceral. Presença de formas amastigotas de Leishmania spp. no interior de macrófagos (seta branca). Panótico Rápido, 400X. (Campo Mourão, 2012).

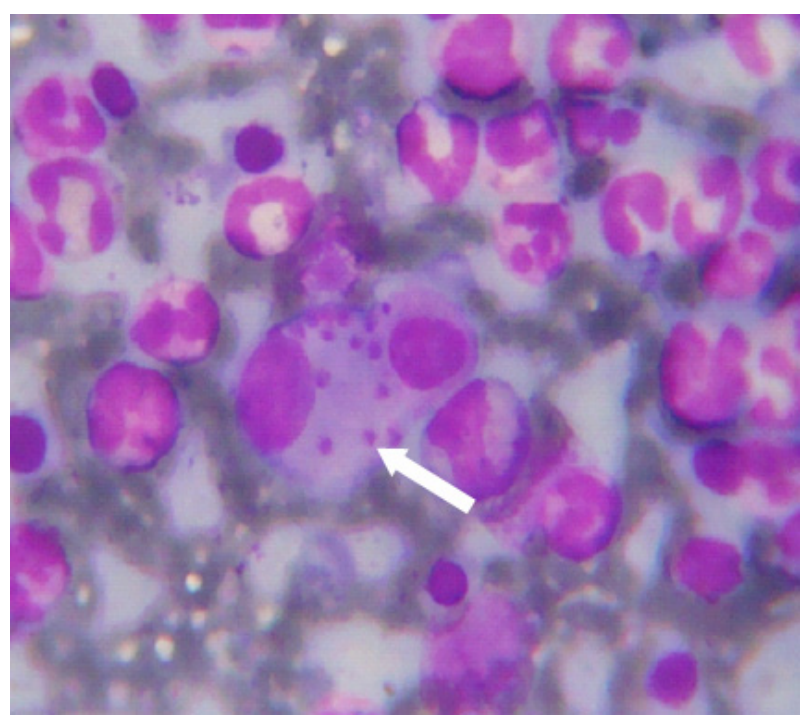

Fonte: Elaboração dos autores.

O caso foi notificado à Secretária da Saúde e Vigilância Sanitária do município, e indicada à realização de eutanásia do paciente, em cumprimento ao Decreto $n^{\circ} .51 .838$ do Ministério da Saúde do Brasil, de 14 de março de 1963, o qual estabelece que animais domésticos portadores de leishmaniose devam ser submetidos à eutanásia, seguindo as recomendações da Resolução $n^{\circ}$. 714, de 20 de junho de 2002, do Conselho Federal de Medicina Veterinária (BRASIL, 2006).
Ao exame necroscópico observou-se coloração pálida difusa das mucosas, hepatoesplenomegalia e linfoadenomegalia generalizada. Cortes histopatológicos dos órgãos linfóides foram realizados e corados com o corante hematológico Panótico Rápido Comercial para posterior avaliação à microscopia de luz no aumento de 100x, com imersão, para pesquisa de formas amastigotas de Leishmania spp. A presença das formas amastigotas de Leishmania spp. foi observada em medula óssea, baço, fígado e linfonodos, evidenciando disseminação sistêmica da enfermidade.

$\mathrm{Na}$ investigação anamnética, o proprietário relatou que possuía mais dois animais de mesma procedência. Em decorrência do resultado positivo para LVC do paciente deste relato e por se tratar de uma zoonose, sugeriram-se os exames sorológicos e citopatológicos nos outros dois cães, que se apresentavam assintomáticos, porém não vacinados contra Leishmania spp. Ambos os testes complementares realizados demonstraram negatividade para a enfermidade.

\section{Resultados, Discussão e Conclusões}

Os sinais clínicos da LVC, associado ao hemograma completo geralmente são inespecíficos e semelhantes a outras doenças infecciosas, tais como erliquiose, babesiose, toxoplasmose, corriqueiramente observadas em cães (BANETH, 2006). Neste caso clínico foram observados emagrecimento, linfoadenomegalia, hipertermia, hepatomegalia, esplenomegalia, alopecia, descamação cutânea, blefarite, conjuntivite, ceratite, condizentes com o observado na literatura (BANETH, 2006; VIDES et al., 2009). Anemia, hiperproteinemia e leucócitos dentro dos valores de normalidades são achados hematológicos frequentes em cães com LV (BANETH, 2006), conforme relatado neste caso.

O diagnóstico para LV muitas vezes é difícil de ser realizado, uma vez que muitas regiões não 
dispõem de laboratórios ou médicos veterinários especializados para arealizaçãodosexames(IKEDAGARCIA; FEITOSA, 2006; MARCONDES et al., 2011). De forma rápida e específica, o diagnóstico de leishmaniose foi firmado após serem detectadas formas amastigotas de Leishmania spp., sugerindo um caso de LV, uma vez que o animal era proveniente de região endêmica para a doença. Apesar de o animal apresenta-se parasitado e com sinais clínicos característicos de LVC, seria boa a realização da técnica da PCR para identificação do DNA do parasita, porém, neste caso, não imprescindível, por se tratar de uma área indene para a doença (IKEDAGARCIA; FEITOSA, 2006; THOMAZ-SOCCOL et al., 2009).

Há alguns anos, a LV apresentou uma expansão para as regiões Norte, Sudeste e Centro-Oeste do país, principalmente no Pará, Tocantins, Mato Grosso do Sul, Minas Gerais e São Paulo, devido à crescente migração urbana, precárias condições sócio-econômicas, desmatamento e mudanças climáticas (BRASIL, 2006). Essa mudança no padrão de transmissão da doença fez com que a Secretaria de Vigilância em Saúde, do Ministério da Saúde, reforçasse a vigilância epidemiológica em regiões consideradas indenes, como a região Sul do país (FREHSE et al., 2010).

No Estado do Paraná tem sido realizado levantamento da fauna flebotomínea em áreas consideradas vulneráveis para transmissão da LV, ou seja, em municípios limítrofes com estados (Mato Grosso do Sul e São Paulo) e países (Paraguai e Argentina) que apresentam casos humanos ou caninos da doença (VIDES et al., 2009; ACARDI et al., 2010). Até os dias atuais, não há relatos da presença do flebotomíneo Lutzomyia longipalpis no Paraná ou em outros estados do Sul do Brasil (FREHSE et al., 2010). Desta forma, os casos caninos e humanos, descrito nessas regiões, são caracterizados como importados ou alóctones (THOMAZ-SOCCOL et al., 2009; BRASIL, 2010).
No município de Campo Mourão, localizado na latitude $24^{\circ} 03 \mathrm{~S}$ e longitude $52^{\circ} 22 \mathrm{~W}$, região CentroOeste do estado do Paraná, não há notificações de casos autóctones caninos e humanos de LV, além da ausência de informações quanto à presença vetorial (BRASIL, 2010).

A maior parte dos médicos veterinários locais não se atenta à possibilidade de seus pacientes serem provenientes de regiões endêmicas para a enfermidade ou que viajam com frequência para outros estados, ignorando a presença de casos alóctones na região. Deve-se ressaltar que esse fato pode agravar a situação epidemiológica da LV no país, uma vez que o parasita, assim como o vetor, vem a cada dia, adaptando-se às novas mudanças, o que pode futuramente, culminar com a adaptação dos mesmos em outras regiões do país (BRASIL, 2006).

Talvez seja fundamental, como uma das formas de prevenção da disseminação da enfermidade, que o Ministério da Agricultura, Pecuária e Abastecimento (MAPA) solicitasse exames sorológicos de triagem, para permitir a entrada de animais de zona endêmica para zona indene. No entanto, resultados falso-negativos podem ocorrer, pois a janela imunológica para a formação de anticorpos pode variar de três meses a anos recomendando-se a inclusão de outros métodos de diagnósticos, como a imunocromatografia e a PCR, como uma das tentativas para o controle da leishmaniose visceral (BANETH, 2006).

Embora, em outubro de 2011, a comercialização e o uso de uma das vacinas contra LV canina tenha sido deferida pelo MAPA (BRASIL, 2011), este método ainda é controverso, uma vez que ainda não foi comprovado, por meio do xenodiagnóstico, que cães vacinados não são transmissores da enfermidade aos vetores. Além disso, o Ministério da Saúde e a OMS não recomendam o uso da vacina em Saúde Pública ou como um método preventivo da LV (BRASIL, 2009; WHO, 2012). Esse fato torna-se ainda mais questionável quando 
deparamos com o caso relatado, o qual o animal, de acordo com o proprietário, fora vacinado contra a doença conforme recomendado pelo fabricante, mas apresentou formas amastigotas de Leishmania spp. na CAAF de linfonodos.

A leishmaniose visceral é uma zoonose emergente, a qual vem aumentando não só em número de casos, mas na sua dispersão geográfica, tornando-se de extrema importância para a Saúde Pública. Desta forma, a investigação sobre a doença, assim como a identificação de casos alóctones em áreas indenes, serve para alertar os veterinários sobre a importância dessa infecção. Atualmente, esses profissionais foram incluídos nos Núcleos de Apoio à Saúde da Família (NASF), conforme a portaria 2.488/2011, ressaltando a importância dos mesmos e a sua constante atuação junto ao Ministério da Saúde.

\section{Referências}

ACARDI, S. A.; LIOTTA, D. J.; SANTINI, M. S.; ROMAGOSA, C. M.; SALOMÓN, O. D. Detection of Leishmania infantum in naturally infected Lutzomyia longipalpis (Diptera: Psychodidae: Phlebotominae) and Canis familiaris in Misiones, Argentina: the first report of a PCR-RFLP and sequencing-based confirmation assay. Memórias do Instituto Oswaldo Cruz, São Paulo, v. 105, n. 6, p. 796-799, 2010.

BANETH, G. Leishmaniasis. In: GREENE, C. E. Infectious diseases of the dog and cat. 3. ed. Philadelphia: Elsevier Saunders, 2006. p. 685-698.

BRASIL. Ministério da Agricultura, Pecuária e Abastecimento. Nota de esclarecimento sobre as vacinas anti-leishmaniose registradas no MAPA. Brasília, DF, [s.n.], 2009. Disponível em: <http://portal.saude. gov.br/portal/arquivos/pdf/leismaniosevisceral_nota esclarecimento27052009.pdf>. Acesso em: $15 \mathrm{dez} .2011$.

Ministério da Saúde. Ministério da Agricultura, Pecuária e Abastecimento. Departamento de Fiscalização de insumos veterinários. Deferimento de alterações diversas. Diário Oficial [da] União, Seção 1, 2011, p. 31. Brasília, DF, 2011. Disponível em: <http: //www.in.gov. br/autenticidade.html.>. Acesso em: 12 jan. 2012.
. Secretaria de Vigilância em Saúde. Departamento de Vigilância Epidemiológica. Casos confirmados e óbitos por leishmaniose visceral, segundo UF de residência. Brasília, DF, [s.n.], 1990-2010. Disponível em: <http: portal.saude.gov.br portal arquivos pdf CASOS CONF_2010LV.pdf>. Acesso em: 12 dez. 2011.

Secretaria de Vigilância em Saúde. Departamento de Vigilância Epidemiológica. Manual de vigilância e controle da leishmaniose visceral. Brasília, DF, [s.n.], 2006. p. 120. Disponível em: <http://portal.saude.gov. br/portal/arquivos/pdf/manual_leish_visceral2006.pdf. $>$. Acesso em: 15 dez. 2011.

FREHSE, M. S.; JÚNIOR, H. G.; ULLMANN, L. S.; CAMOSSI, L. G.; MACHADO, J. G.; LANGONI, H.; BIONDO, A. W.; MOLENTO, M. B. Surveillance of canine visceral leishmaniasis in a disease-free area. Revista Brasileira de Parasitologia Veterinária, São Carlos, v. 19, n. 1, p. 64-66, 2010.

IKEDA-GARCIA, F. A.; FEITOSA, M. M. Métodos de diagnóstico da leishmaniose visceral canina. Clínica Veterinária, São Paulo, n. 62, p. 32-38, 2006.

MARCONDES, M.; BIONDO, A. W.; GOMES, A. A. D.; SILVA, A. R. S.; VIEIRA, R. F. C.; CAMACHO, A. A.; QUINNG, J.; CHANDRASHEKARG, R. Validation of a Leishmania infantum ELISA rapid test for serological diagnosis of Leishmania chagasi in dogs. Veterinary Parasitology, Philadelphia, v. 175, n. 1, p. 15-19, 2011.

THOMAZ-SOCCOL, V.; CASTRO, E. A.; NAVARRO, I. T.; FARIAS, M. R.; SOUZA, L. M.; CARVALHO, Y.; BISPO, S.; MEMBRIVE, N. A.; MINOZZO, J. C.; TRUPPEL, J.; BUENO, W.; LUZ, E. Casos alóctones de leishmaniose visceral canina no Paraná, Brasil: implicações epidemiológicas. Revista Brasileira de Parasitologia Veterinária, São Carlos, v. 18, n. 3, p. 4651, 2009.

VIDES, J. P.; GOMES, A. A. D.; SOBRINHO, L. S. V.; MARCONDES, M. Clinical aspect from dogs naturally infected with visceral leishmaniasis in Araçatuba - São Paulo State (Brazil). In: WORLD SMALL ANIMAL VETERINARY ASSOCIATION CONGRESS (WSAVA), 34., 2009, São Paulo. Proceedings... São Paulo: Guará, 2009. p. 105-106.

WORLD HEALTH ORGANIZATION - WHO. Leishmaniasis. 2012. Disponível em: <http://www.who. int/ topics/leishmaniasis/en/>. Acesso em: 10 jan. 2012. 